\title{
Presynaptic Control of Modulatory Fibers by Their Neural Network Targets
}

\author{
Michael P. Nusbaum, ${ }^{1,2}$ James M. Weimann, ${ }^{1}$ Jorge Golowasch, ${ }^{1, a}$ and Eve Marder' \\ 'Department of Biology, Brandeis University, Waltham, Massuchusetts 02254 and ${ }^{2}$ Neurobiology Research Center, \\ Department of Physiology and Biophysics, University of Alabama at Birmingham, Birmingham, Alabama 35294
}

\begin{abstract}
Numerous modulatory fibers control the output of the pyloric and gastric mill neural networks in the crustacean stomatogastric ganglion (STG). We now describe the first results of intracellular recordings from the axon of one of these input neurons, stomatogastric nerve axon 1 (SNAX 1), close to where it enters the STG. SNAX 1 excites both the pyloric and gastric mill rhythms and is identified on the basis of its synaptic interactions with identified STG neurons. SNAX 1 receives synaptic input from several sources within the STG. As a result of these synaptic inputs, SNAX 1 fires bursts of action potentials that are time-locked to both the pyloric and gastric mill rhythms. The synaptic connections made onto the SNAX axon terminals are likely to play important roles in shaping the impulse activity patterns in these modulatory inputs. Thus, the fibers that modulate the pattern-generating networks in the STG are themselves influenced by elements in these networks, and modulation is a dynamic interaction between input fibers and STG neurons.
\end{abstract}

A large body of work has shown that many modulatory inputs influence the activity patterns of rhythmically active neural networks (Harris-Warrick and Marder, 1991). For example, modulatory input fibers from other ganglia exert considerable influence on the activity of the pyloric and gastric mill rhythms of the stomatogastric ganglion (STG) of decapod crustaceans. These fibers all enter the STG via the stomatogastric nerve (stn), which is the sole connection between the STG and the rest of the CNS. In the crab Cancer borealis, there are about 60 fibers of large and medium diameter in the stn (M. J. Coleman, M. P. Nusbaum, I. Cournil, and B. J. Claiborne, unpublished observations), of which 10 originate from somata in the STG. Most of the remaining fibers originate from somata in the commissural $(\mathrm{COG})$ and esophageal (OG) ganglia, and are likely to provide modulatory inputs to the STG.

Single modulatory neurons can activate entire networks of neurons and can play major roles in shaping the motor patterns of the STG (Sigvardt and Mulloney, 1982a,b; Nagy and Dickinson, 1983; Nusbaum and Marder, 1989a,b; Dickinson et al.,

Received Nov. 20, 1991; revised Feb. 7, 1992; accepted Feb. 11, 1992

This research was supported by U.S. Public Health Service Grants NS17813 (E.M.), BNS-8909613 (M.P.N.), and NS29436 (M.P.N.) and by the Human Frontier Science Program.

Correspondence should be addressed to Dr. Michael P. Nusbaum, Neurobiology Research Center, Department of Physiology and Biophysics, University of Alabama at Birmingham, Volker Hall-G78s, Birmingham, AL 35294.

aPresent address: Laboratoire de Neurobiologie, Ecole Normale Superieure, 46 rue d'Ulm, Paris 75005 France.

Copyright (C) 1992 Society for Neuroscience $0270-6474 / 92 / 122706-09 \$ 05.00 / 0$
1990; Meyrand et al., 1991). Previously identified modulatory neurons in this system include the inferior ventricular neurons (Dando and Selverston, 1972; Claiborne and Selverston, 1984), the anterior pyloric modulator (Dickinson and Nagy, 1983; Nagy and Dickinson, 1983), the commissural gastric neurons (Robertson and Moulins, 1984; Simmers and Moulins, 1988a,b), the modulatory proctolin-containing neurons (Nusbaum and Marder, 1989a,b), the gastro/pyloric receptor neurons (Katz et al., 1989; Katz and Harris-Warrick, 1990), and the pyloric suppressor neurons (Cazalets et al., 1990; Meyrand et al., 1991). These identified modulatory neurons account for approximately $15-20$ of the axons in the stn.

The previous work on modulatory neurons employed intrasomatic recordings. However, since the somata of these neurons are a long distance from the STG, somatic recordings do not provide information about potential synaptic interactions at their axon terminals in the STG. This limitation of intrasomatic recordings is common to many systems. Despite a wealth of anatomical and biochemical evidence for presynaptic receptors on terminals of CNS neurons, to our knowledge there are no previous examples of direct electrophysiological recordings at or close to nerve terminals in neurons involved in modulating networks.

In this article, we show intracellular recordings from a newly identified, modulatory STG input neuron, at a site electrically close to the STG neuropil. These recordings show that there are large-amplitude synaptic potentials evoked in the stomatogastric nerve axon (SNAX) terminals by neurons of the STG. Not only do these recordings allow us to study these presynaptic contacts, but they also demonstrate that the patterns of activity in inputs to the STG are themselves modified by local interactions between the terminals and the STG neurons.

Some of these data have appeared previously in abstract form (Nusbaum, 1991).

\section{Materials and Methods}

Animals. Cancer borealis were obtained from Neptune Seafood (Boston, MA) and from Marine Biological Laboratory (Woods Hole, MA). Crabs were maintained until used in refrigerated $\left(10-13^{\circ} \mathrm{C}\right)$, aerated aquaria with circulating artificial seawater. Data were obtained from 50 male crabs weighing between 300 and $800 \mathrm{gm}$.

Solutions. $C$. borealis physiological saline contained (in $\mathrm{mmol} / \mathrm{liter}$ ) $\mathrm{NaCl}, 440 ; \mathrm{KCl}, 11 ; \mathrm{MgCl}_{2}, 26 ; \mathrm{CaCl}_{2}, 13$; Trizma base, 10; and maleic acid, $5 ; \mathrm{pH} 7.4-7.5$. Descending impulse activity to the STG was blocked in some preparations by applying isotonic $(750 \mathrm{~mm})$ sucrose to Vaseline wells surrounding either the desheathed stn or both desheathed CoGs.

Anatomy. Intracellular Lucifer yellow (LY) dye-fills were made with microelectrodes (40-80 M $\Omega$ ) whose tips were filled with $5 \% \mathrm{LY}-\mathrm{CH}$ (Sigma or Molecular Probes) in water. The shaft was back-filled with 1 $M \mathrm{LiCl}$, keeping an air bubble between the two solutions. LY was ion- 


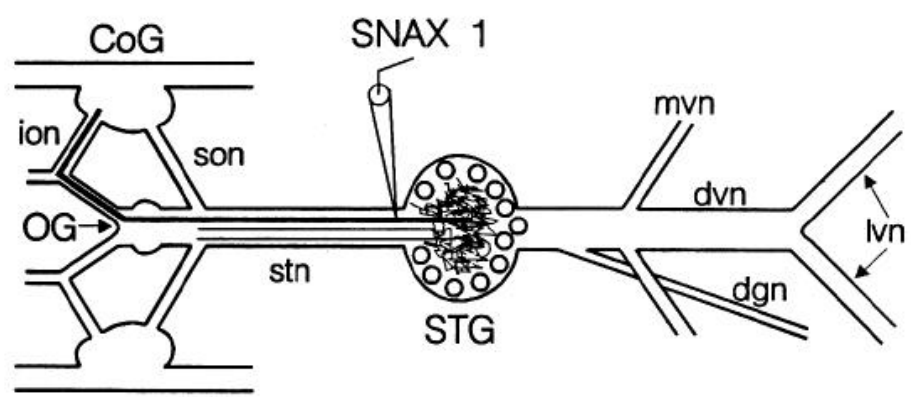

Figure 1. Schematic illustration of the stomatogastric nervous system, including several SNAX axons. The microelectrode is shown at the approximate location from which intra-axonal recordings were performed. $d g n$, dorsal gastric nerve; $d v n$, dorsal ventricular nerve; ion, inferior esophageal nerve; $l v n$, lateral ventricular nerve; $m v n$, medial ventricular nerve; son, superior esophageal nerve; stn, stomatogastric nerve.

tophoresed for 5-20 min, using either DC hyperpolarizing current ( -1 to $-5 \mathrm{nA})$ or hyperpolarizing current pulses (1 Hz frequency, $500 \mathrm{msec}$ duration, -1 to $-5 \mathrm{nA}$ amplitude). LY-filled whole-mount preparations were fixed with $4 \%$ paraformaldehyde (in $0.1 \mathrm{M} \mathrm{NaPO}_{4}, \mathrm{pH} \mathrm{7.3)} \mathrm{for} \mathrm{4-}$ $12 \mathrm{hr}$. They were then rinsed five times, at $1 \mathrm{hr}$ intervals, with $0.1 \mathrm{M}$ $\mathrm{NaPO}_{4}(\mathrm{pH} 7.3$ ). These preparations were mounted with $80 \%$ glycerol and $20 \% 20 \mathrm{~mm}$ sodium carbonate (pH 9.5) and then viewed and photographed with either a Zeiss IM35 or Nikon Optiphot fluorescence microscope, equipped with fluorescein optics.

Electrophysiology. Experiments were performed on the stomatogastric nervous system, which includes the paired CoGs, the unpaired OG and STG ganglia, plus their connecting and motor nerves (Fig. 1). Preparations in which the STG remained connected with the CoG and OG are termed "combined preparations." For studying gastric mill activity we sometimes used a semi-intact, combined preparation in which the lateral ventricular nerve innervation to the muscles of the pyloric chamber and the gastric mill remained intact. In other preparations, the STG was disconnected from both the CoGs, and OG by either placing a sucrose block on the stn or cutting this nerve. In some preparations, the CoGs were individually sucrose blocked, leaving only the OG in communication with the STG.

Intracellular and extracellular recordings were made using routine methods for the STG (Selverston and Moulins, 1987). STG motor neurons were identified according to the muscles that they innervate (Maynard and Dando, 1974). The crab innervation patterns that we used to identify the motor neurons are described in Hooper et al. (1986) and Weimann et al. (1991). The stn and all ganglia were desheathed to facilitate intracellular recordings. Intracellular recordings were performed while visualizing the preparation with white light transmitted through a dark-field condenser (Leitz). Intracellular recordings from STG neurons were made using 4 м K-acetate (KAc)-filled microelectrodes $(15-40 \mathrm{M} \Omega)$. The first intra-axonal recording in a preparation was made with an LY-filled microelectrode, while KAc-filled microelectrodes were used for subsequent intra-axonal recordings. Data were collected on chart recorder (Gould ES1000 or AstroMed TM 95000) and RC Electronics Computerscope with a $386 / 25 \mathrm{MHz}$ IBM PC. Preparations were continuously superfused $(7-15 \mathrm{ml} / \mathrm{min}$ ) with physiological saline that was cooled to $10-13^{\circ} \mathrm{C}$. Bath volume was $5-10 \mathrm{ml}$.

\section{Results}

At the entrance to the STG, many of the axons in the desheathed stn are readily visualized. Most of these axons have diameters in the range of 3-10 $\mu \mathrm{m}$ (Coleman, Nusbaum, Cournil, and Claiborne, unpublished observations). We found that we could visually guide a microelectrode to a particular axon, impale that axon, and maintain the intra-axonal recording for as long as several hours. The SNAX impalement site was routinely within $200 \mu \mathrm{m}$ of the anterior edge of the STG neuropil (Fig. 1). Figure 2 shows an LY fill of an identified axon, SNAX 1. This figure illustrates many of the general features of the stn inputs to the STG. As was usual for these dye-fills, the dye traveled anteriorly

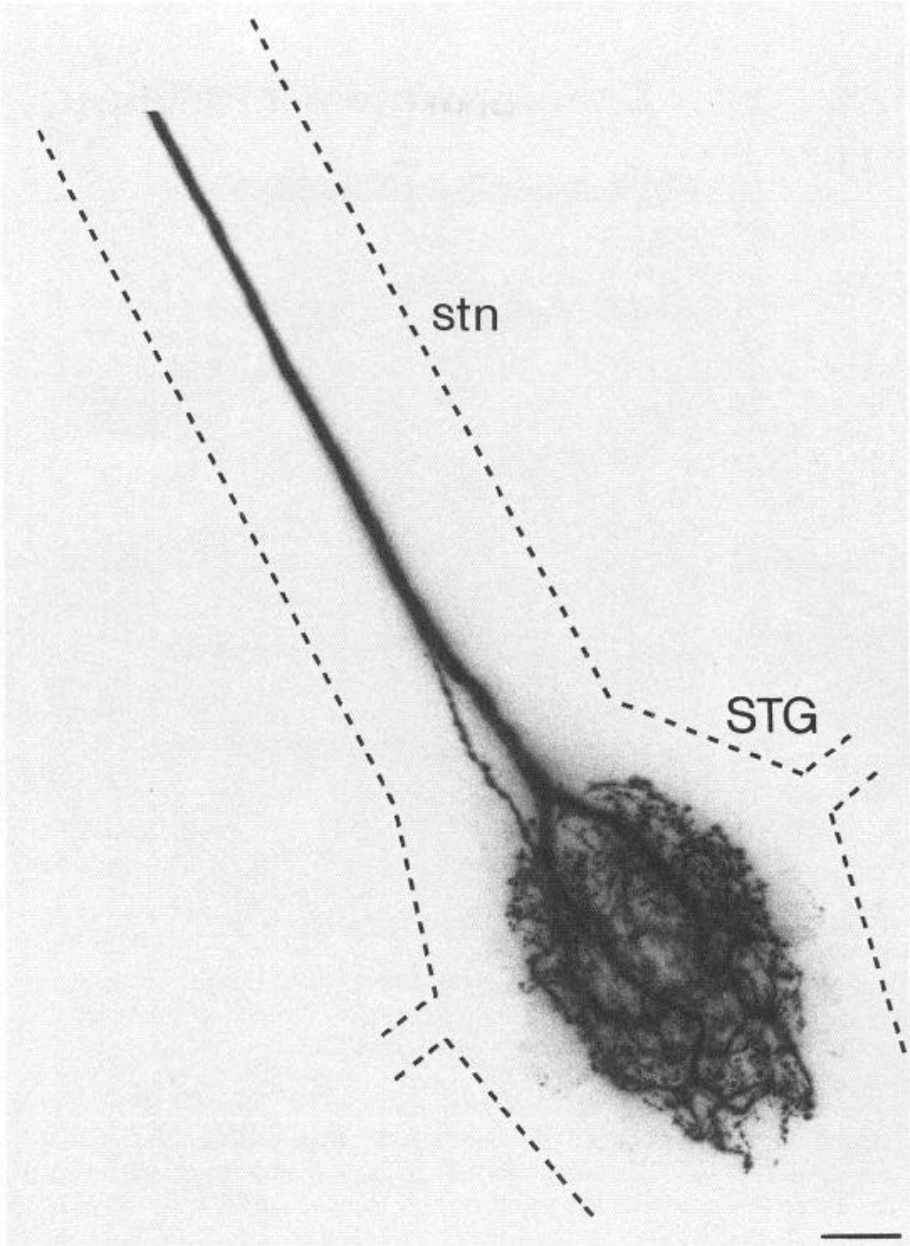

Figure 2. Intracellular LY dye fill of SNAX 1. As the SNAX 1 axon enters the STG, it splits into several branches, from which many fine processes extend to fill the STG neuropil. Note that within the STG, the SNAX 1 arbor is restricted to the neuropil and no cell body is labeled. Note also that the SNAX 1 axon extends anteriorly within the stn. SNAX 1 recording and dye-filling site was just anterior to the start of the STG neuropil. Scale bar, $100 \mu \mathrm{m}$.

for a considerable distance in the stn, but never traveled far enough to reach either the OG or the CoGs (Fig. 2). Note also that there are no LY-labeled somata in the STG, but the LYlabeled terminals of the filled fiber ramify profusely throughout the STG neuropil. (In the crab STG, the cell bodies form a single-cell layer around the perimeter of the neuropil, as shown schematically in Fig. 1).

We were able to identify reliably at least 10 different SNAX axons, and some of these were consistently found in almost all experiments. In this article we will focus on the properties of SNAX 1, which is identified on the basis of a series of physiological and anatomical criteria, as we describe below.

\section{Identification of SNAX 1}

The axon we call SNAX 1 has strong physiological actions on the STG networks, and it receives synaptic inputs from identified STG neurons. SNAX 1 typically has a resting potential of about $-60 \mathrm{mV}$, and its action potential is often overshooting. The SNAX 1 action potential can be recorded extracellularly from the stn (Fig. $3 A$ ), where its action potential amplitude is similar to that of the pyloric pacemaker neuron, the anterior 

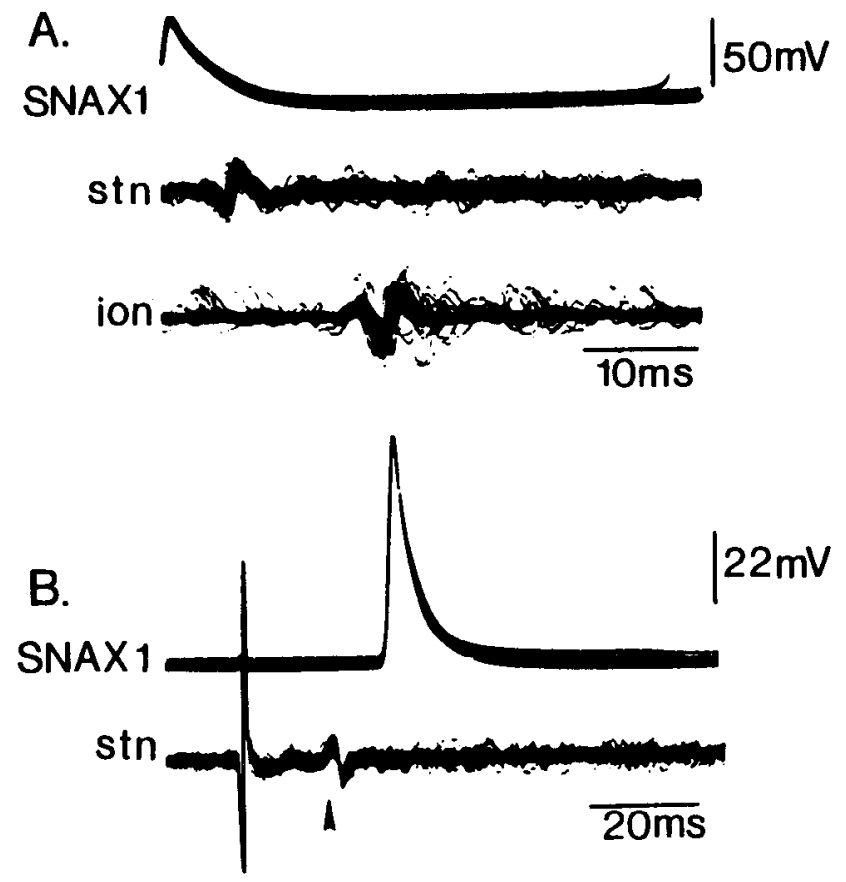

Figure 3. Electrophysiological determination of the SNAX 1 axon pathway. $A$, Superimposed oscilloscope sweeps triggered by SNAX 1 action potentials that were elicited by intracellular depolarizing current injection. Each intracellularly recorded SNAX 1 action potential was followed by a time-locked, extracellularly recorded action potential that occurred first in the $\operatorname{stn}$ and then in the right ion. $B$, Superimposed oscilloscope sweeps showing the result of brief $(0.5 \mathrm{msec}$ duration) extracellular stimulation of the right ion that was above threshold for eliciting an SNAX 1 action potential. Each ion stimulation was followed by an action potential recorded first in the extracellular $\sin$ recording (arrowhead) and then in the intracellular SNAX $l$ recording. A largeamplitude stimulus artifact is evident in the stn recording. $A$ and $B$ are from the same preparation. Extracellular stn recording site was anterior (toward the supcrior esophageal nerve/stn junction) to the intracellular SNAX 1 recording site.

burster (AB) neuron. The SNAX 1 action potential is recorded, as a medium-sized unit, in only one of the inferior esophageal nerves (ions) (Fig. $3 A$ ) and in neither of the superior esophageal nerves. Brief $(0.5 \mathrm{msec})$ shocks of the appropriate ion elicited the SNAX 1 action potential. Following each ion stimulation, the SNAX 1 action potential was recorded first in the extracellular stn recording, and then intracellularly in the axon close to the STG (Fig. 3B).

SNAX 1 strongly excites the pyloric rhythm if the preparation is relatively quiet before SNAX 1 is stimulated. For example, in the experiment shown in Figure 4, the extracellular recording of the dorsal ventricular nerve (dvn) shows slow and irregular firing before SNAX 1 was stimulated. When SNAX 1 was depolarized to fire action potentials, a full pyloric rhythm was elicited. This can be seen as rhythmic bursts of alternating activity in the lateral pyloric (LP; large unit on the dvn) and pyloric dilator (PD; medium-sized unit) neurons. In this preparation, the STG was isolated by transecting the stn, demonstrating that SNAX 1 has a spike initiation site close to the STG. Despite constant intracellular depolarization of SNAX 1, the impulse activity of this axon was periodically interrupted (Fig. 4). These interruptions originated from two sources. SNAX 1 activity decreased during each PD neuron burst, and it also received large-amplitude IPSPs that were not time-locked to the pyloric rhythm but were from the lateral gastric (LG) neuron.

SNAX 1 also has strong excitatory effects on gastric mill neurons. For example, intracellular depolarization of SNAX 1 excites the LG and dorsal gastric (DG) neurons (Fig. 5). Note that SNAX 1 activity depolarized the DG neuron sufficiently for it to fire action potentials during the entire time that SNAX 1 remained active. In all preparations $(n=5)$ in which we made simultaneous intracellular recordings from SNAX 1 and DG, SNAX 1 excitation of DG was never accompanied by discernable PSPs. However, SNAX 1 evoked clear EPSPs in the LG neuron (Fig. 5). Figure 5 also shows that SNAX 1 continued to fire action potentials after the stimulation was terminated and that these impulses were interrupted during each PD neuron burst. This spontaneous activity was sufficient to maintain DG neuron impulse activity until SNAX 1 stopped firing.

\section{Synaptic interactions between SNAX I and $L G$}

The EPSPs evoked by SNAX 1 in LG follow every SNAX 1 action potential with a short and constant latency (Fig. 6A). In some recordings from $\mathrm{LG}$ we also recorded a fast, small-amplitude depolarization that preceded the EPSP and occurred simultaneously to the action potential in SNAX 1, suggesting that this might be a coupling potential from LG. Further evi-

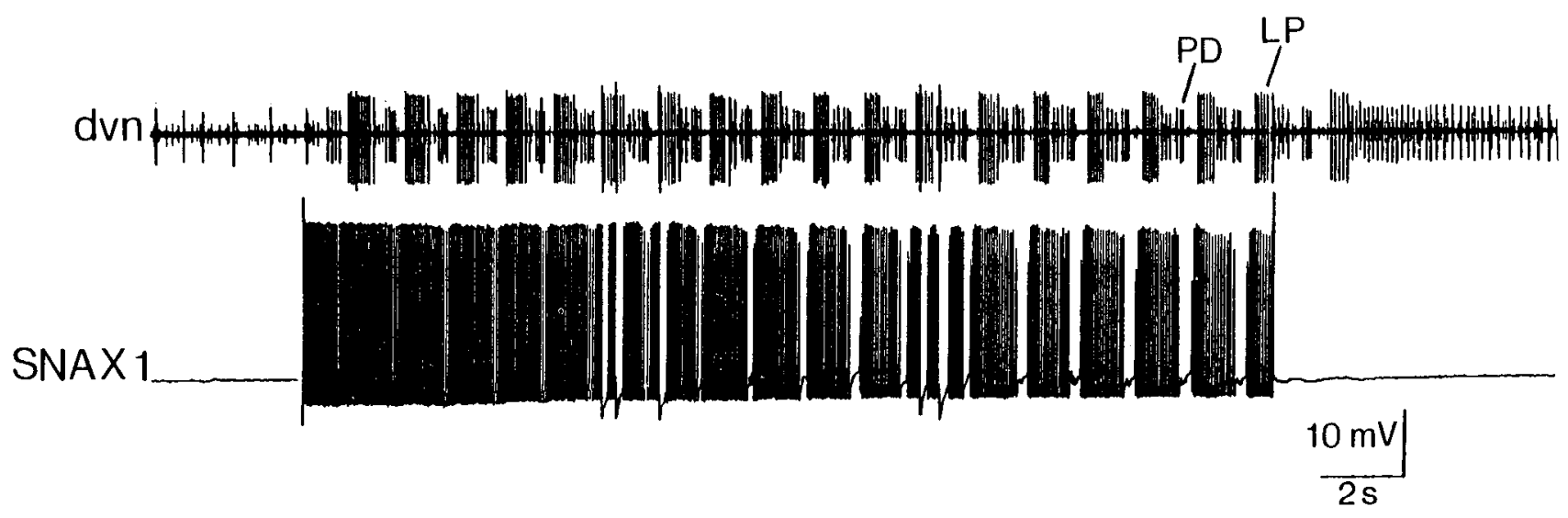

Figure 4. SNAX 1 initiates the pyloric rhythm in a completely isolated STG. Impulse activity in $S N A X 1$, resulting from constant-amplitude depolarizing current injection into SNAX 1 for the duration of its activity, activated the pyloric rhythm. Rhythmic pyloric activity, recorded extracellularly in the $d v n$, is represented here by the activity of two pyloric neurons, the $L P$ and $P D$ neurons. SNAX 1 resting potential was -65 $\mathrm{mV}$. STG was isolated by transecting the stn anteriorly to the SNAX 1 recording site. 


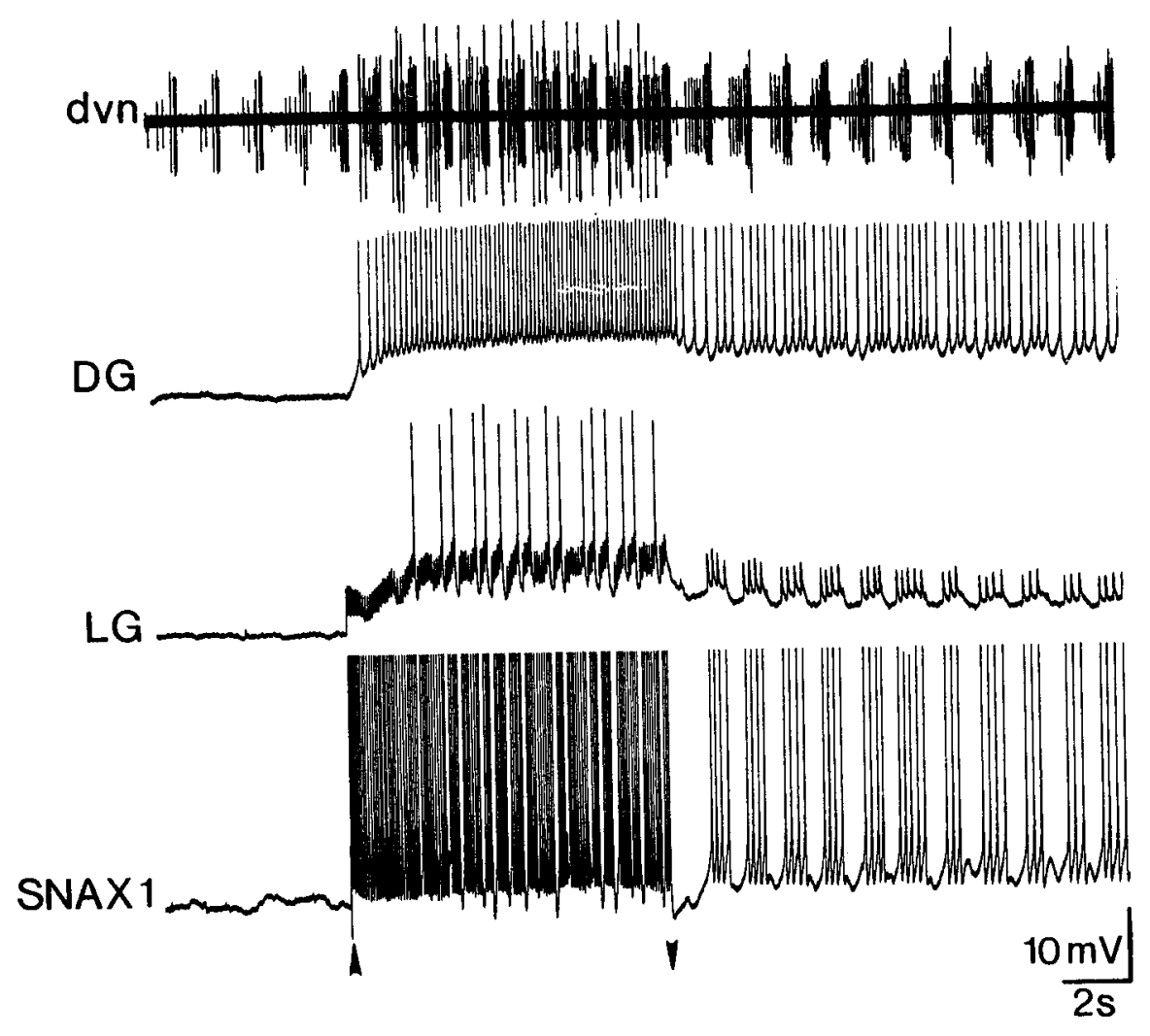

Figure 5. Intracellular stimulation of SNAX I (between arrowheads) excites the $L G$ and $D G$ neurons, and strengthens the pyloric rhythm ( $d v n)$. The largest unit in the dvn recording is the $L G$ neuron. The small- and medium-sized, rhythmically active units in the dvn are the pyloric (PY) constrictor and PD neurons, respectively. Following termination of SNAX 1 stimulation, $S N A X$ $I$ impulse activity persisted and continued to influcnce LG, DG, and the pyloric rhythm. Post-stimulus activity in SNAX 1 was time-locked to the pyloric rhythm. SNAX 1 resting potential was $-60 \mathrm{mV}$. Recordings were from a combined preparation. The peaks of the SNAX $I$ action potentials were clipped by the chart recorder. dence that supported the possibility that LG and SNAX 1 are electrically coupled is shown in Figure $6 B$. Here, hyperpolarizing current pulses applied to SNAX 1 resulted in hyperpolarization of the LG ncuron. Both the hypcrpolarizing "coupling potentials" and the rapid small-amplitude $(1 \mathrm{mV})$ depolarizations, but not the EPSPs, persisted in saline containing $20 \mathrm{~mm} \mathrm{Co}^{2+}$ and $1.3 \mathrm{~mm} \mathrm{Ca}^{2+}(0.1 N)$ to suppress chemical synaptic transmission.

SNAX 1 received synaptic potentials from the LG neuron. Each LG action potential evoked a short, constant-latency, smallamplitude EPSP that was followed immediately by an IPSP in SNAX 1 (Fig. 7 $A$ ). The short latency of the EPSP from LG to SNAX 1 suggested that it might be an electrotonic potential. In fact, when hyperpolarizing current was injected into $L G$, in either normal saline (Fig. $7 B$ ) or $20 \mathrm{~mm} \mathrm{Co}^{2+}$ saline, SNAX 1 was also hyperpolarized until the termination of current injection into LG. The LG-mediated IPSP was more effective than the LG-mediated EPSP in influencing the activity level of SNAX 1. As a result, SNAX 1 activity decreased during $L G$ neuron activity. For example, as shown in Figure 8, a burst of impulses in LG suppressed the impulse activity of SNAX 1. Thus, LG appears to be electrically coupled to the STG terminals of SNAX 1 and also to inhibit these terminals synaptically.

In summary, an stn fiber is called SNAX 1 if it excites $L G$ and DG, receives an EPSP/IPSP from LG, exhibits small-amplitude membrane potential oscillations that are time-lockcd to an ongoing pyloric rhythm, and excites an initially silent or weak pyloric rhythm. All of these criteria have been met in every preparation $(>20)$ in which we have identified SNAX 1. There appear to be two SNAX 1 neurons in the stn, with each one
A.

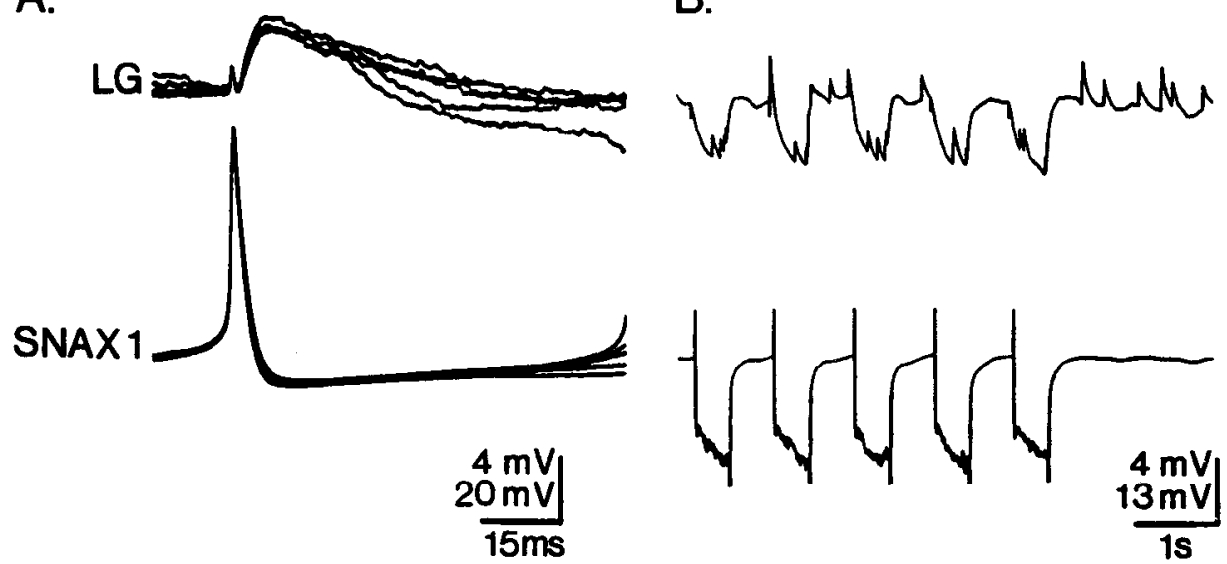

Figure 6. SNAX 1 synaptic effects on the LG neuron. $A$, Five superimposed sweeps triggered by SNAX 1 action potentials, each elicited by intracellular stimulation. Each SNAX 1 action potential caused, in $L G$, the appearance of a small-amplitude depolarizing potential with no measureable latency, followed by a short-latency EPSP. Resting potentials: SNAX $1,-44 \mathrm{mV}$; LG, $-52 \mathrm{mV}$. Preparation was a completely isolated STG. $B$, Constant-amplitude $(-3 \mathrm{nA})$ and constant-duration (500 msec) hyperpolarizing current pulses injected into SNAX 1 (resting potential, $-62 \mathrm{mV}$ ) each caused a hyperpolarization in $L G$ (resting potential, $-52 \mathrm{mV}$ ). Recordings were from a combincd preparation. $A$ and $B$ are from different preparations. 


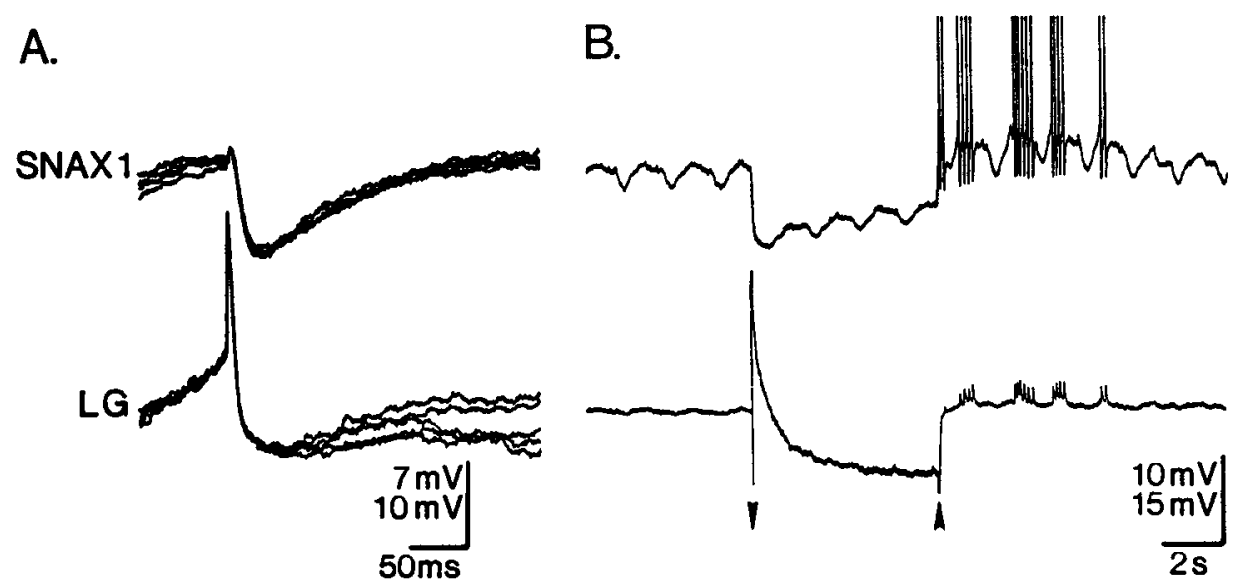

Figure 7. LG neuron synaptic effects onto SNAX 1. A, Five superimposed sweeps triggered by LG action potentials, each elicited by intracellular stimulation. Each $L G$ action potential caused, in $S N A X 1$, the appearance of a small-amplitude depolarizing potential with no measureable latency, followed by a short-latency IPSP. Resting potentials: LG, $-48 \mathrm{mV}$; SNAX 1, $-41 \mathrm{mV}$. Recordings were from a completely isolated STG. $B$, IIyperpolarizing current ( $4 \mathrm{nA}$; arrowheads) injected into $L G$ (resting potential, $-52 \mathrm{mV}$ ) caused a hyperpolarization in $S N A X 1$ (resting potential, $-45 \mathrm{mV}$ ). SNAX 1 fired action potentials (peaks clipped by chart recorder) upon rebound from hyperpolarization, producing EPSPs in $L G$. Smallamplitude membrane potential oscillations in $S N A X 1$ represent rhythmic inhibition from the pyloric rhythm. Recordings were from a combined preparation. $A$ is from the same preparation as Figure $6 A$. $A$ and $B$ are from different preparations.

extending anteriorly in the stn and then extending into one of the ions. In one experiment, we obtained simultaneous recordings from two different SNAX 1 axons and found no evidence of interactions between them. In no preparation have we found more than two SNAX 1 axons, nor have we recorded from another SNAX that was difficult to distinguish from SNAX 1.

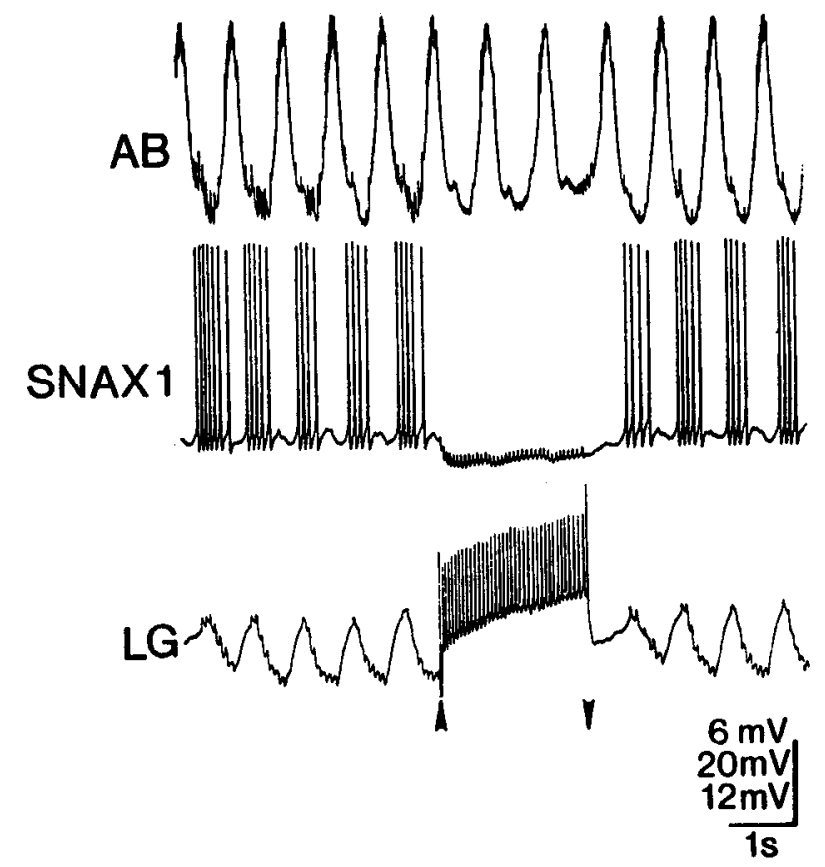

Figure 8. LG neuron inhibition of SNAX 1 is functionally effective. Intracellular stimulation of $L G$ (arrowheads) caused a sustained hyperpolarization that suppressed pyloric-timed impulse activity in $S N A X 1$ (SNAX 1 resting potential, $-45 \mathrm{mV}$ ). EPSPs/IPSPs are evident in $S N A X$ $I$ during $L G$ stimulation. Pyloric rhythm was monitored by intracellular recording of the $A B$ neuron, the pyloric pacemaker neuron. The membranc potential range of the slow wave oscillations in neuron $A B$ was $-40 \mathrm{mV}$ (peak) to $-60 \mathrm{mV}$ (trough). The slow wave oscillations in the $L G$ neuron ranged from $-42 \mathrm{mV}$ (peak) to $-52 \mathrm{mV}$ (trough).

\section{SNAX 1 excites the gastric mill rhythm}

The ability of SNAX 1 to excite several gastric mill neurons suggested that SNAX 1 might also activate the gastric mill rhythm. Indeed, in either semi-intact or combined preparations, SNAX 1 did initiate the gastric mill rhythm. In the experiment shown in Figure $9 A$, there was an ongoing pyloric rhythm in the absence of SNAX I stimulation, but no ongoing gastric mill rhythm. The gastric mill neurons were either tonically active (c.g., GM) or silent (e.g., DG, large unit in the right-hand dgn recording in Fig. $9 B$, and $L G$ ). When SNAX 1 was depolarized (Fig. $9 B$ ), the gastric mill rhythm was activated for the duration of SNAX 1 stimulation. The DG, GM, and LG neurons fired in a vigorous gastric mill rhythm and the pyloric IC neuron was regularly interrupted during each gastric mill cycle, as has been reported previously (Weimann et al., 1991). Rhythmic gastric mill activity often stopped within one cycle after SNAX 1 stopped firing.

Even when we steadily depolarized SNAX 1, its activity was regularly inhibited at the onset of each LG neuron impulse burst. This inhibition was most pronounced at the onset of each LG burst and then apparently decreased, because SNAX 1 resumed firing before an LG burst ended. However, the SNAX 1 firing frequency was consistently highest when LG was not firing action potentials, suggesting that some LG-mediated inhibition of SNAX 1 persisted for the duration of LG activity.

\section{Presynaptic regulation of $S N A X 1$ activity}

Figures 4 and 9 show that during tonic depolarization of SNAX 1 , its activity was modulated by activity in other neurons. This is seen more clearly in Figure 10, which demonstrates strong modulation of SNAX 1 activity in phase with both the gastric mill and pyluric rhythms. In this experiment, a robust pyloric rhythm and a relatively weak gastric mill rhythm were in progress in the absence of SNAX 1 activity (Fig. 10A). The pyloric rhythm is most readily seen in the dvn recording, where the large-amplitude impulse bursts that occur approximately every $1 \mathrm{sec}$ are the pyloric-timed activity of the LP neuron (arrowheads). The pyloric rhythm is also reflected in the small-am- 
A.

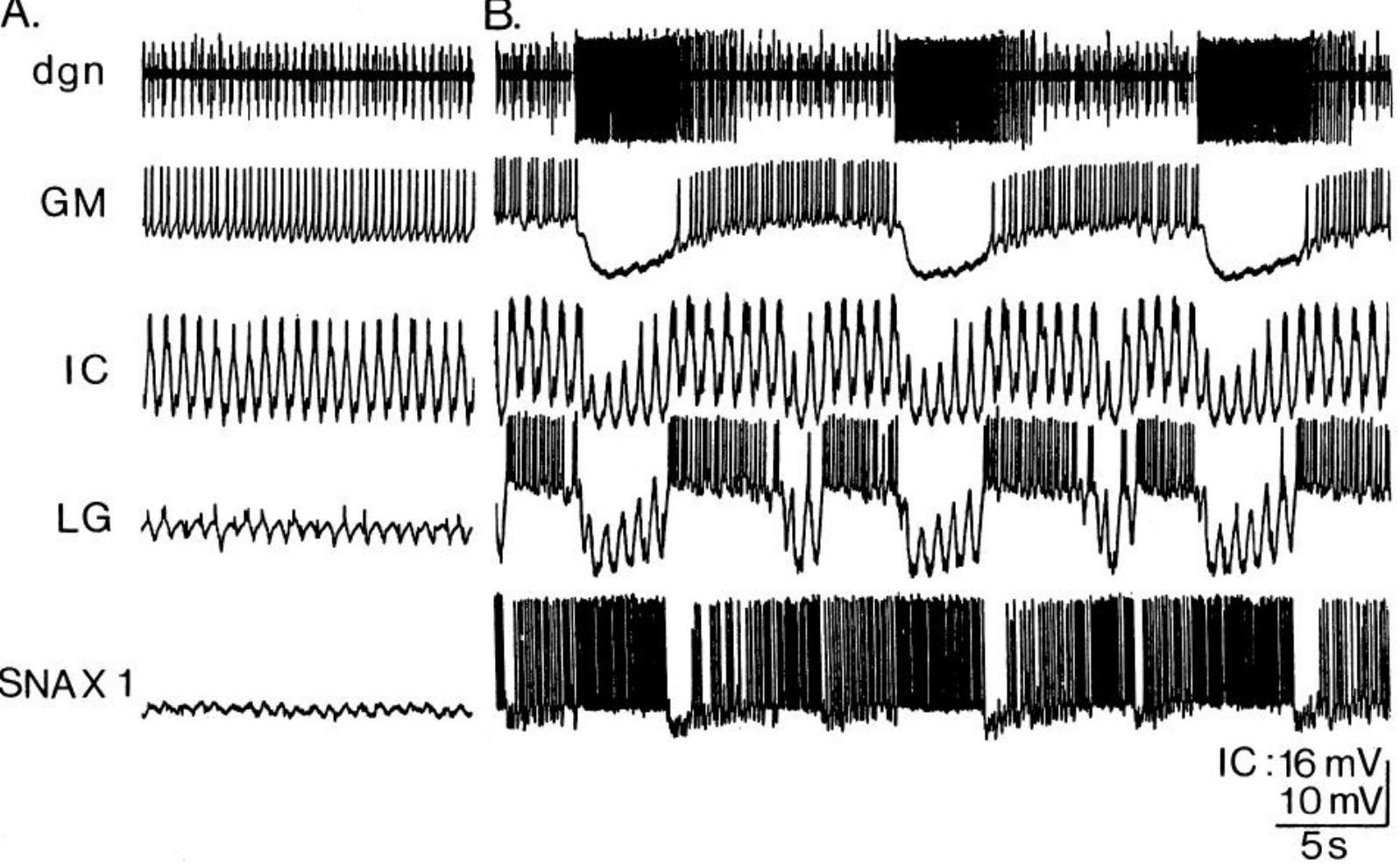

Figure 9. SNAX 1 initiates the gastric mill rhythm and exhibits impulse activity bursts that are time-locked to that rhythm. $A$, In the absence of SNAX 1 activity there was an ongoing pyloric rhythm (inferior cardiac [IC] neuron), but no gastric mill rhythm (extracellular $d g n$, intracellular gastric mill $[G M]$ and $L G$ neurons). $B$, Several seconds later, during constant-amplitude depolarizing current injection $(+1 \mathrm{nA})$ into $S N A X 1$, pyloric activity was strengthened and the gastric mill rhythm was elicited. Despite a constant level of stimulation, SNAX 1 impulse activity was rhythmically suppressed or reduced. These interruptions resulted from synaptic inhibition from the $L G$ neuron. $S N A X 1$ stimulation was begun before, and persisted for the duration of, the episode shown in $B . S N A X 1$ resting potential, $-48 \mathrm{mV}$. Dorsal gastric $(D G)$ neuron is largest unit in $d g n$. $A$ and $B$ were from the same, semi-intact preparation.

A.
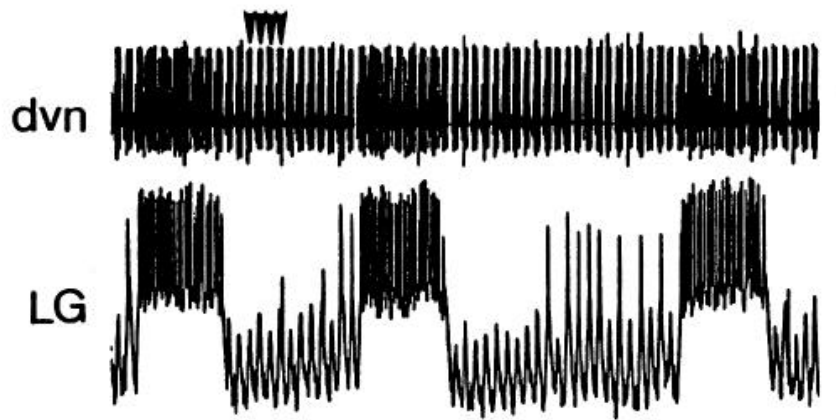

SNAX 1
B.
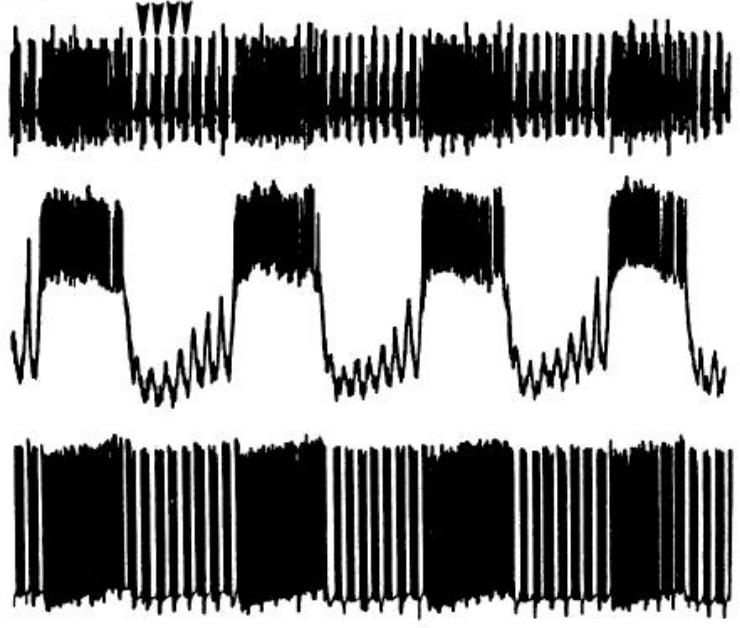

Figure 10. SNAX 1 enhances the gastric mill rhythm and exhibits patterned impulse activity that is time-locked to both the pyloric and gastric mill rhythms. A, When SNAX 1 was not firing action potentials, there was a vigorous pyloric rhythm (dvn recording: arrowheads mark four consecutive LP neuron bursts) and a weak gastric mill rhythm ( $L G$ neuron recording). $B$, When $S N A X I$ was stimulated with constant-amplitude depolarizing current $(+1 \mathrm{nA})$, the pyloric cycle frequency slowed down and the gastric mill rhythm was strengthened. Despite constant level of stimulation, SNAX 1 fired rhythmically with both the gastric mill and pyloric rhythms. SNAX 1 resting potential, $-36 \mathrm{mV}$. $A$ and $B$ were from the same, semi-intact preparation. 
plitude, interburst oscillations in the LG neuron recording. The $\mathrm{LG}$ recording also shows the frequency of the gastric mill rhythm. In the control condition, SNAX 1 received tonic IPSPs from an unknown source. Additionally, during each LG neuron burst one can see what appears at the slow sweep speed of this figure to be a small fuzz of synaptic potentials in SNAX 1. These are the EPSP/IPSPs that are caused by LG impulse activity. When SNAX 1 was depolarized (Fig. 10B), the pyloric rhythm frequency was slightly decreased (arrowheads) but the frequency and intensity of the gastric mill rhythm were strongly enhanced. In this preparation, SNAX 1 fired during the entire duration of each episode of LG neuron activity. Note, however, that the action potentials occurring at the onset of each such SNAX 1 impulse burst originate from a more hyperpolarized potential than did those occurring later in each burst. This presumably reflects the IPSPs that SNAX 1 receives from the LG neuron. Additionally, in this preparation, during each LG neuron interburst interval the SNAX 1 impulse activity is repeatedly interrupted in time with each cycle of the pyloric rhythm.

\section{Discussion}

For many years the notion of a "command" neuron was prevalent. Implicit in the first definitions of "command" neurons was that these neurons were part of an unidirectional flow of information in which these neurons controlled the output of the network upon which they acted. Later work demonstrated that the activity pattern of "command elements" was shaped by feedback from the pattern-generating network that they influenced (Weeks, 1981; Nusbaum and Kristan, 1986; Chiel et al., 1988; McCrohan, 1988). The recordings from axons of modulatory inputs to the STG allow us to see, for the first time, the synaptic connections made onto the modulatory neurons at their sites of interaction with their target networks. Knowing that the feedback to individual SNAX axons occurs locally within the STG will enable us to use this preparation to determine better the functional consequences of this feedback.

\section{Identification of $S N A X 1$}

We have used intra-axonal recordings to identify and characterize SNAX 1, a modulatory neuron that extends an axon to the STG and, within this ganglion, excites the pyloric and gastric mill rhythms in the crab Cancer borealis. There appear to be two SNAX 1 neurons, each of which projects to one CoG via the ion. This conclusion is supported by preliminary anatomical data (Coleman, Nusbaum, Cournil, and Claiborne, unpublished observations) suggesting that there is only one SNAX 1 soma in each CoG. SNAX 1 does not appear to be any of the previously identified STG input neurons. We have also identified and begun characterization of SNAX 2-10 (M. P. Nusbaum, unpublished observations).

\section{Are the SNAX axons part of the STG pattern-generating network?}

It has become increasingly difficult to decide when individual neurons should be considered members of a pattern-generating network (Marder and Weimann, 1992), and this is demonstrated by the example of SNAX 1 and the gastric mill network. Historically, the gastric mill network neurons within the STG were thought to comprise the entire gastric mill network (Mulloney and Selverston, 1974a,b; Selverston and Mulloney, 1974). Subsequently, neurons in the CoGs were found that activated and modulated the gastric mill network (Robertson and Moulins,
1984; Nagy et al, 1988), and which in turn were influenced by sensory feedback from gastric mill muscles (Simmers and Moulins, 1988a,b). Unlike the polysynaptic, multiganglionic pathways previously described (Simmers and Moulins, 1988a,b), the interactions between the gastric mill neuron LG and SNAX 1 are local and occur within the neuropil of the STG.

SNAX 1 appears to have bidirectional interactions with at least one gastric mill neuron and to have direct electrical access to the gastric mill network. SNAX 1 receives IPSPs from the LG neuron that time-lock SNAX 1 activity to the gastric mill rhythm. Because SNAX 1 and LG are electrically coupled, SNAX 1 has direct electrical access to the gastric mill network. As a result of this coupling, the level of polarization in SNAX 1 will influence the activity of the gastric network, even when it is not firing action potentials (Kepler et al., 1990). Moreover, SNAX 1 probably provides phasic information as well as modulatory input to the gastric mill network, since it evokes discrete EPSPs in several gastric mill neurons and a slow excitation in others (present results; Nusbaum, unpublished observations). Therefore, SNAX 1 is both a modulator and a component of the gastric mill network.

\section{Multiple spike-initiating zones: do modulatory inputs also provide efference copy?}

Many neurons in the crustacean stomatogastric system have multiple spike initiation sites (Vedel and Moulins, 1978; Nusbaum and Marder, 1989a; Meyrand et al., 1992). Multiple spike initiation sites are also a common feature of neurons in many systems (Korn and Bennett, 1971; Llinas and Nicholson, 1971; Calabrese, 1980; Haydon and Winlow, 1982). Commonly, action potentials in STG input neurons are initiated in the CoG or $\mathrm{OG}$, or in the periphery, and they propagate to the STG. However, all SNAX axons from which we have recorded, including SNAX 1 (Figs. 4, 6A), can also initiate action potentials at the STG. If SNAX axons initiate action potentials in the STG, they will influence the STG networks, be rhythmically shaped by these networks, and also provide efference copy of the resulting rhythmic activity to other regions of the nervous system. Activation of an SNAX within the STG might result from synaptic connections with STG neurons, such as those influencing SNAX 1, and/or from the release of a neuromodulator by a different SNAX.

Under many circumstances, the alteration of the SNAX 1 activity pattern by the pyloric and gastric mill networks is likely to be restricted to the STG, leaving SNAX 1 activity in other regions of the nervous system unaffected. This is because the small amplitude of the inhibitory feedback to SNAX 1 is not likely to spread effectively to the CoGs (which are approximately $2 \mathrm{~cm}$ distant from the STG). Thus, STG input neurons, such as SNAX 1, may well be exhibiting different activity patterns, at any one time, within their arborizations in different ganglia.

\section{Role of presynaptic regulation of modulatory inputs}

Presynaptic effects regulate neurotransmission at many levels within the nervous system. For example, primary afferent terminals in many systems receive presynaptic inhibition, via depolarizing and/or hyperpolarizing IPSPs (Solodkin et al., 1984; Kirk, 1985; Cattaert et al., 1990). Edwards (1990) showed that depolarizing IPSPs effectively reduce the excitability of a neuron via several mechanisms. He also suggested that, because depolarizing IPSPs cannot prime a neuron for rebound excitation, they would be inappropriate for influencing a rhythmically ac- 
tive neuron unless that neuron also received synaptic excitation. Rhythmically active neurons that receive hyperpolarizing IPSPs might fire by postinhibitory rebound (Mulloney and Selverston, 1974b; Selverston and Mulloney, 1974; Satterlie, 1985) or escape from inhibition (Angstadt and Calabrese, 1989). The presence of hyperpolarizing IPSPs in an SNAX might enable it to initiate rhythmic action potential bursts from its STG spikeinitiating zone, even when that SNAX is not generating action potentials in its ganglion of origin.

Relatively little is known about the presence and function of presynaptic influences within neural networks. During fictive locomotion in both the cat spinal cord and crayfish nerve cord, however, primary afferent terminals receive rhythmic presynaptic input that appears to originate from activity of the central locomotor network (Sillar and Skorupski, 1986; Skorupski and Sillar, 1986; Gossard et al., 1989; Cattaert et al., 1990). In these preparations it has been suggested that this presynaptic input mediates the gating of spinal reflexes that occurs during locomotion. More recently, intra-axonal recordings of spinal interneurons revealed the presence of membrane potential oscillations that were time-locked to the ongoing locomotor rhythm in the lamprey (Alford et al., 1991). However, the source and the function of this rhythmic input remain obscure.

\section{Implications for transmitter release}

Many of the identified STG input neurons (including the SNAX) contain both a neuropeptide and a small molecule transmitter (Harris-Warrick et al., 1992). Therefore, the rhythmic feedback onto SNAX may have important consequences for the dynamics of small molecule and peptide transmitter release. Neuromodulation tends to involve relatively long-duration effects that extend over many cycles of rhythmic activity, while conventional transmission has short-lasting effects that influence only a fraction of each cycle (Marder and Meyrand, 1989). While the long-lasting effects of peptide modulators might not require the modulatory neuron to be rhythmically active, this rhythmic activity might help maintain appropriate levels of release of that peptide. Modulatory peptides are optimally released by relatively high-frequency firing, and peptidergic neurons often exhibit rhythmic bursting activity, while small molecule transmitter release is less sensitive to activity patterns (Cazalis et al., 1985; Lundbcrg ct al., 1986; Nagano and Cooke, 1987; Bartfai et al., 1988; Whim and Lloyd, 1990; Peng and Horn, 1991). Therefore, the rhythmic modulation of SNAX by STG interactions may coordinately optimize the release of a peptide while ensuring that a co-released conventional transmitter elicits appropriately timed phasic effects.

In conclusion, the electrical proximity of our intra-axonal recordings to the sites of synaptic interaction within the STG neuropil has enabled us to identify directly the presence, as well as the source, of synaptic feedback onto the STG terminals of SNAX 1. Our ability to record these events in the STG terminals of extrinsic inputs will now enable us to determine directly the role of such local circuit interactions in shaping the patterned neural output produced by neural network activity.

\section{References}

Alford S, Christenson J, Grillner S (1991) Presynaptic GABA and $\mathrm{GABA}_{\mathrm{B}}$ receptor-mediated phasic modulation in axons of spinal motor interneurons. Eur J Neurosci 3:107-117.

Angstadt JD, Calabrese RL (1989) A hyperpolarization-activated inward current in heart interneurons of the medicinal leech. J Neurosci 9:2846-2857.
Bartfai T, Iverfeldt K, Fisone G, Serfozo P (1988) Regulation of the release of coexisting transmitters. Annu Rev Pharmacol Toxicol 28: 285-310.

Calabrese RL (1980) Control of multiple impulse-initiation sites in a leech interneuron. J Neurophysiol 44:878-896.

Cattaert D, El Manira A, Marchand A, Clarac F (1990) Central control of the sensory afferent terminals from a leg chordotonal organ in crayfish in vitro preparation. Neurosci Lett 108:81-87.

Cazalets JR, Nagy F, Moulins M (1990) Suppressive control of the crustacean pyloric network by an identified neuron. I. Modulation of the motor pattern. J Neurosci 10:448-457.

Cazalis M, Dayanithi G, Nordmann JJ (1985) The role of patterned burst and interburst interval on the excitation-coupling mechanism in the isolated rat neural lobe. J Physiol (Lond) 369:45-60.

Chiel HJ, Kupfermann I, Weiss KR (1988) An identified histaminergic neuron can modulate the outputs of buccal-cerebral interneurons in Aplysia via presynaptic inhibition. J Neurosci 8:49-63.

Claiborne BJ, Selverston AI (1984) Localization of stomatogastric IV neuron cell bodies in lobster brain. J Comp Physiol 154:27-32.

Dando MR, Selverston AI (1972) Command fibers from the supraesophageal to the stomatogastric ganglion in Panulirus argus. J Comp Physiol 78:138-175.

Dickinson PS, Nagy F (1983) Control of a central pattern generator by an identified modulatory interneurone in Crustacea. II. Induction and modification of plateau properties in pyloric neurones. J Exp Biol 105:59-82.

Dickinson PS, Mecsas C, Marder E (1990) Neuropeptide fusion of two motor pattern generator circuits. Nature 344:155-158.

Edwards DH (1990) Mechanisms of depolarizing inhibition at the crayfish giant motor synapse. I. Electrophysiology. J Neurophysiol 64:532-540.

Gossard J-P, Cabelguen J-M, Rossignol S (1989) Intra-axonal recordings of cutaneous primary afferents during fictive locomotion in the cat. J Neurophysiol 5:1177-1188.

Harris-Warrick RM, Marder E (1991) Modulation of neural networks for behavior. Annu Rev Neurosci 14:39-57.

Harris-Warrick RM, Nagy F, Nusbaum MP (1992) Neuromodulation of stomatogastric networks by identified neurons and transmitters. In: The stomatogastric nervous system: a model biological neural network (Harris-Warrick RM, Marder E, Moulins M, Selverston AI, eds), in press. Boston: MIT Press/Bradford.

Haydon PG, Winlow W (1982) Multipolar neurones of Lymnaea stagnalis. I. Multiple spike initiation sites and propagation failure allow neuronal compartmentalization. J Comp Physiol 147:503-510.

Hooper SL, O'Neil MB, Wagner R, Ewer J, Golowasch J, Marder E (1986) The innervation of the pyloric region of the crab, Cancer borealis: homologous muscles in decapod species are differently innervated. J Comp Physiol 159:227-240.

Katz PS, Harris-Warrick RM (1990) Neuromodulation of the crab pyloric central pattern generator by serotonergic/cholinergic proprioceptive afferents. J Neurosci 10:1495-1512.

Katz PS, Eigg MH, Harris-Warrick RM (1989) Serotonergic/cholinergic muscle receptor cells in the crab stomatogastric nervous system. I. Identification and charactcrization of the gastropyloric receptor cells. J Neurophysiol 62:558-570.

Kepler TB, Marder E, Abbott LF (1990) The effect of electrical coupling on the frequency of model neuronal oscillators. Science 248 : 83-85.

Kirk MD (1985) Presynaptic inhibition in the crayfish CNS: pathways and synaptic mechanisms. J Neurophysiol 54:1305-1325.

Korn H, Bennett MVL (1971) Dendritic and somatic impulse initiation in fish oculomotor neurons during vestibular nystagmus. Brain Res 27:169-175.

Llinas R, Nicholson C (1971) Electrophysiological properties of dendrites and somata in alligator Purkinje cells. J Neurophysiol 34:532551 .

Lundberg JM, Rudehill A, Sollevi A, Theodorsson-Norheim E, Hamberger B (1986) Frequency- and reserpine-dependent chemical coding of sympathetic transmission: differential release of noradrenaline and neuropeptide $Y$ from pig spleen. Neurosci Lett 63:96-100.

Marder E, Meyrand P (1989) Chemical modulation of an oscillatory neural circuit. In: Neuronal and chemical oscillators (Jacklet JW, ed), pp 317-338. New York: Dekker.

Marder E, Weimann JM (1992) Modulatory control of multiple task processing in the stomatogastric nervous system. In: Neurobiology of 
motor programme selection: new approaches to mechanisms of behavioral choice (Kien J, McCrohan C, Winlow W, eds), in press. Manchester: Manchester UP.

Maynard DM, Dando MR (1974) The structure of the stomatogastric neuromuscular system in Callinectes sapidus, Homarus americanus and Panulirus argus (Decapoda Crustacea). Philos Trans R Soc Lond [Biol] 268:161-220.

McCrohan CR (1988) Modification of central pattern generation in invertebrates. Comp Biochem Physiol [A] 90:17-22.

Meyrand P, Simmers J, Moulins M (1991) Construction of a patterngenerating circuit with neurons of different networks. Nature 351:6063.

Meyrand P, Weimann JM, Marder E (1992) Multiple axonal spike initiation zones in a motor neuron: serotonin activation. J Neurosci 12: in press.

Mulloney B, Selverston AI (1974a) Organization of the stomatogastric ganglion of the spiny lobster. I. Neurons driving the lateral teeth. $J$ Comp Physiol 91:1-32.

Mulloney B, Selverston AI (1974b) Organization of the stomatogastric ganglion of the spiny lobster. III. Coordination of the two subsets of the gastric system. J Comp Physiol 91:53-78.

Nagano M, Cooke IM (1987) Comparison of electrical responses of terminals, axons, and somata of a peptidergic neurosecretory system. J Neurosci 7:634-648.

Nagy F, Dickinson PS (1983) Control of a central pattern generator by an identified modulatory interneurone in Crustacea. I. Modulation of the pyloric motor output. J Exp Biol 105:33-58.

Nagy F, Dickinson PS, Moulins M (1988) Control by an identified modulatory neuron of the sequential expression of platedu properties of, and synaptic inputs to, a neuron in a central pattern generator. $J$ Neurosci 8:2875-2886.

Nusbaum MP (1991) Local interactions of descending inputs with rhythmically active neural networks. Soc Neurosci Abstr 17:1490.

Nusbaum MP, Kristan WB Jr (1986) Swim initiation in the leech by serotonin-containing interneurones, cells 21 and 61. J Exp Biol 122: 277-302.

Nusbaum MP, Marder F. (1989a) A modulatory proctolin-containing neuron (MPN). I. Identification and characterization. J Neurosci 9: 1591-1599.

Nusbaum MP, Marder E (1989b) A modulatory proctolin-containing neuron (MPN). II. State-dependent modulation of rhythmic motor activity. J Neurosci 9:1600-1607.

Peng Y, Horn JP (1991) Continuous repetitive stimuli are more effective than bursts for evoking LHRH release in bullfrog sympathetic ganglia. J Neurosci 11:85-95.
Robertson RM, Moulins M (1984) Oscillatory command input to the motor pattern generators of the crustacean stomatogastric ganglion. II. The gastric rhythm. J Comp Physiol 154:473-491.

Satterlie RA (1985) Reciprocal inhibition and post-inhibitory rebound produce reverberations in locomotor pattern generator. Science 229 : $402-404$

Selverston AI, Moulins M (1987) The crustacean stomatogastric system: a model for the study of central nervous systems. Heidelberg: Springer.

Selverston AI, Mulloney B (1974) Organization of the stomatogastric ganglion of the spiny lobster. II. Neurons driving the medial tooth. J Comp Physiol 91:33-51.

Sigvardt KA, Mulloney B (1982a) Sensory alteration of motor patterns in the stomatogastric nervous system of the spiny lobster Panulirus inlerruplus. J Exp Biol 97:137-1 52.

Sigvardt KA, Mulloney B (1982b) Properties of synapses made by IVN command-interneurones in the stomatogastric ganglion of the spiny lobster Panulirus interruptus. J Exp Biol 97:153-168.

Sillar KT, Skorupski P (1986) Central input to primary afferent neurons in crayfish, Pacifastacus leniusculus, is correlated with rhythmic motor output of thoracic ganglia. J Neurophysiol 55:678-688.

Simmers J, Moulins M (1988a) A disynaptic sensorimotor pathway in the lobster stomatogastric system. J Neurophysiol 59:740-756.

Simmers J, Moulins M (1988b) Nonlinear interneuronal properties underlie integrative flexibility in a lobster disynaptic sensori-motor pathway. J Neurophysiol 59:757-777.

Skorupski P, Sillar KT (1986) Phase-dependent reversal of reflexes mediated by the thoracocoxal muscle receptor organ in the crayfish, Pacifasticus leniusculus. J Neurophysiol 55:689-695.

Solodkin M, Jimenez I, Rudomin P (1984) Identification of common interneurons mediating pre- and postsynaptic inhibition in the cat spinal cord. Science 224:1453-1456.

Vedel JP, Moulins M (1978) A motor neuron involved in two centrally generated motor patterns by means of two different spike initiating sites. Brain Res 138:347-352.

Weeks JC (1981) Neuronal basis of leech swimming: separation of swim initiation, pattern generation, and intersegmental coordination by selective lesions. J Neurophysiol 45:698-723.

Weimann JM, Meyrand P, Marder E (1991) Neurons that form multiple pattern generators: identification and multiple activity patterns of gastric/pyloric neurons in the crab stomatogastric system. J Neurophysiol $65: 111-122$.

Whim MD, Lloyd PE (1990) Neuropeptide cotransmitters released from an identified cholinergic motor neuron modulate neuromuscular efficacy in Aplysia. J Neurosci 10:3313-3322. 